\title{
ATUALIZACOES
}

\section{IMUNOBIOLOGIA DA CISTICERCOSE: AVALIAÇÃO DOS CONCEITOS ATUAIS}

\author{
A. Spina-França *
}

Embora seja problema que interessa principalmente à Medicina das regiões tropicais, a cisticercose tem sido assinalạda em outras áreas. Ela é comum na maioria dos países da América Latina, destacando-se a freqüência com que é referida em certas regióes do México, do Brasil e do Peru. Nos Estados Unidos da América do Norte a doença é rara, embora os pesquisadores norte-americanos venham demonstrando mais interêsse por essa parasitose nos últimos anos ${ }^{11}, \mathbf{5 2}^{2}$, pois apesar dos casos parecerem depender, em sua maioria, de infestação de pacientes provindos do Exterior, já há certa preocupação com a possibilidade da infestação autóctone, em algumas das regiões dos Estados Unidos para onde confluem correntes migratórias oriundas de países nos quais a doença é comum ${ }^{10,22}$.

É das áreas em que a cisticercose ocorre com maior freqüência que procede a maioria dos estudos sôbre a doença, mas o interêsse da maioria dos investigadores tem-se voltado para os aspectos relativos ao diagnóstico e ao tratamento da doença. Pouco tem sido publicado sôbre a imunologia da cisticercose, e assim, neste trabalho de revisão, a maior parte dos dados foi reunida de modo indireto, mediante busca de dados laboratoriais incluídos em trabalhos de indole clínica.

Nesse particular a situação dos conhecimentos sôbre a imunobiologia da cisticercose não difere daquela que caracteriza a maioria dos aspectos imunológicos do parasitismo por protozoários e por outros metazoários. Poucos são os conhecimentos sôbre o assunto, conforme foi salientado pela Comissão de Especialistas em Imunologia e Moléstias Tropicais da Organização Mundial de Saúde que assinalou algumas das razões que explicam a precariedade de tais conhecimentos ${ }^{6}$. Em relação aos parasitos, foram apontados os fatôres dependentes da complexidade estrutural, das diferentes fases de desenvolvimento e de diferenciação próprias ao ciclo evolutivo de cada um dêles e suas múltiplas possibilidades de localização no hospedeiro. Além disso, os estudos têm sido dificultados pela precariedade dos métodos de cultivo dos parasitos e dos conhecimentos sôbre a especificidade relativamente estrita de hospedeiro. Por outro lado, é restrita ainda a aplicação da imunologia aos estudos de parasitologia; mesmo da aplicação dos recursos clássicos de imunodiagnóstico (reações de fixação do complemento, reações de precipitação,

Do Departamento de Neurologia da Faculdade de Medicina, Universidade de São Paulo: * Professor-assistente. 
cutirreaçōes) não tem resultado progressos que se comparem aos obtidos pela aplicação dêsses métodos em bacteriologia.

Em relação ao hospedeiro, menciona essa Comissão os problemas ligados aos desenvolvimento dos parasitos no homem e aos mecanismos imunitários que ocorrem no organismo dêste último. Destacam-se aquêles relativos às possibilidades de, no hospedeiro, serem satisfeitas as exigências nutricionais dos parasitos e serem preenchidas condiçóes que tornem viável tanto a invasão inicial, como migracoóes ulteriores e a sobrevida no local do seu desenvolvimento definitivo. Foi destacada a possibilidade de o organismo humano produzir substâncias tóxicas ou anticorpos capazes de inibir o crescimento dos parasitos ou de destrui-los, sendo ventiladas questões relativas às reações imunitárias.

Os dados até hoje obtidos sôbre a cisticercose permitem as mesmas conclusões, pois muitas questões permanecem obscuras. No entanto, é possível reunir certo número de conhecimentos sôbre a imunopatologia especialmente graças a dados histopatológicos e laboratoriais fornecidos pela cisticercose do sistema nervoso central (SNC), localização que tem motivado o maior número de pesquisas, resultando tal interêsse da evolução tórpida e quase sempre inexorável, configurando-se a neurocisticercose como uma das mais sérias afecções parasitárias do SNC.

Neste estudo de síntese e de atualização serão considerados, sucessivamente, fatôres ligados ao parasito e ao organismo parasitado, assim como aspectos da reação histopatológica e da reação imunológica.

Aspectos parasitológicos - Quando chegam à cavidade gástrica humana ovos viáveis da Taenia solium (Linnaeus, 1756) e a carapaça quitinosa que os envolve é destruída, os embriões liberados tendem a atravessar a mucosa e são levados para os diversos tecidos em que podem completar seu desenvolvimento. Não se conhecem as razões pelas quais o embrião se desenvolve, de preferência, em certos tecidos do homem. Pode-se admitir que essa preferência seja o resultado da interação de pelo menos dois fatôres; o primeiro seria o da possibilidade de existirem nos tecidos produtos indispensáveis à nutrição do parasito; o segundo estaria relacionado a fenômenos locais de imunidade que impediriam a fixação dos parasitos em certos tecidos determinando sua morte e destruição.

Qualquer que seja o mecanismo, os parasitos desenvolvem-se, especialmente, no SNC e leptomeninges, no globo ocular, na tela subcutânea e no conjuntivo interfascicular dos músculos estriados. Embora sejam descritos casos em que os parasitos são indiferentemente distribuídos entre essas várias estruturas, não é incomuum serem êles encontrados em apenas uma delas. Segundo alguns autores, a idade do hospedeiro poderia desempenhar certo papel no estabelecimento da sede do desenvolvimento parasitário ${ }^{4}$ : assim, os tecidos que participam das estruturas do globo ocular seriam infestados mais freqüentemente na primeira década da vida; já a infestação do SNC seria mais comum entre os 20 e 40 anos de idade.

Ao atingir o tecido onde se dará seu desenvolvimento ulterior, o embrião atravessa a parede dos capilares arteriais e se localiza nas estruturas circunvizinhas. Admite-se que após 3 a 4 meses complete-se o desenvolvimento da forma larvária, o Cysticercus cellulosae (Rudolphi, 1808). Pouco 
se conhece sôbre as fases iniciais do desenvolvimento dos cisticercos; as diferenças na forma e no tamanho parecem depender da sua adaptação à disposição das estruturas circunvizinhas. Assim, no tecido conjuntivo interfascicular dos músculos, desenvolvem-se sob forma alongada, cujo longo eixo se orienta segundo a direção das fibras musculares. No parênquima nervoso, apresentam-se os cisticercos sob forma esferoidal, com dimensões variáveis.

As diferentes porções que constituem o corpo do parasito acham-se invaginadas na vesícula e são formadas por camadas superpostas: a mais externa ou cuticular, a média (rica em células) e a interna ou muscular. $\mathrm{Na}$ intimidade desta última, formando a parte central do corpo, encontra-se tecido conjuntivo frouxo em que se diferenciam canalículos excretórios que vão até o poro de invaginação do corpo da larva na vesícula. A parede da vesícula, por sua vez, é formada por várias camadas: a delimitante externa, a fibro-canalicular, a das células arredondadas e a reticulo-fibrilar. Esta últim delimita internamente a parede do cisto e está em contato com o líquido que o preenche. ${ }^{49}$

Ao que tudo indica, é a parede da vesícula a principal responsável pela nutrição do parasito. Os numerosos canalículos que se encontram na segunda camada da sua parede acham-se ligados a ampolas, provàvelmente com funções digestórias, e parecem desempenhar papel importante na elaboração dos produtos retirados do organismo do hospedeiro e necessários à nutrição do cisticerco. Considera-se que a alimentção do corpo da larva que se encontra invaginada no cisto se faça mediante o líquido contido na vesícula. Os produtos finais do seu metabolismo seriam eliminados através do poro situado ao nível do ponto de invaginação do corpo na vesícula. O líquido contido na vesícula é límpido e composto por água, sais minerais e proteínas; estas atingem uma concentração ao redor de $2,9 \%$, podendo estar relacionadas à capacidade antigênica.

No SNC o cisticerco desenvolve tanto no parênquima como nas cavidades e espaços em que está contido o líquido cefalorraqueano (LCR). A localização do parasito no sistema nervoso apresenta uma distribuição até certo ponto preferencial, pois a localização intrarraqueana é menos freqüente que a intracraniana ${ }^{37}$. Nesta última sucedem-se, em ordem de freqüência, a localização no cérebro e meninges, nos ventrículos, nos núcleos cinzentos da base e no cerebelo.

Quando o cisticerco se localiza no parênquima nervoso atinge tamanhos variáveis que parecem depender das condições que oferecem as estruturas circunvizinhas ${ }^{47}$. Em geral, os cisticercos maiores caracterizam os casos em que se encontram poucos parasitos no encéfalo. Quando a infestação cerebral é intensa, as vesículas costumam ser menores e, ao degenerar-se, apresentam tendência a calcificações.

É especialmente quando se localiza nas cisternas da base do encéfalo que pode observar-se o desenvolvimento de uma forma especial do parasito, o Cysticercus racemosus (Zenker, 1822). Permanece ainda desconhecido o mecanismo pelo qual desaparecem a cabeça e o colo do cisticerco a partir da vesícula primária e formam-se novas vesículas. dando origem ao conjunto 
racemoso. As paredes das vesículas dêste último, embora mais espessas, não apresentam delimitação nítida entre suas várias camadas: sua função nutritiva, no entanto, parece ser também bastante diferenciada ${ }^{49}$. O cisticerco racemoso costuma apresentar grandes dimensões; o conjunto das vesículas que o constitui freqüentemente atinge cêrca de $10 \mathrm{~cm}$ na sua maior dimensão.

E variável o tempo de sobrevida do cisticerco. Em geral, é no SNC que permanece viável por períodos de tempo mais longos. Admite-se como têrmo médio, que a sobrevida seja de 3 a 6 anos. Entretanto, já foram registrados casos em que não se podia excluir tempo de vida bem maior (até cêrca de 20 anos). Nos casos em que numerosos cisticercos são encontrados no SNC, embora na provável dependência de um único episódio de infestação, é variável a fase evolutiva em que os parasitos se apresentam.

Cisticercos podem permanecer no organismo humano durante muito tempo sem determinar reações apreciáveis. Assim sendo, compreende-se porque não são observados, na cisticercose humana, fenômenos de hipersensibilidade e reações alérgicas gerais. A fase inicial de invasão e de disseminação dos embrióes costuma passar desapercebida, da mesma forma que a infestação de diversos órgãos pode não ser acompanhada de sintomatologia que leve - paciente a buscar tratamento. $\mathrm{Na}$ cisticercose cutânea as alterações têm caráter quase exclusivamente estético. A cisticercose muscular raramente se acompanha de manifestações clínicas e o seu diagnóstico é baseado no achado radiológico de imagens sugestivas de cisticercos calcificados. Alterações cardíacas podem marcar a presença do parasito no miocárdio. A localização do cisticerco nas estruturas do globo ocular é freqüentemente acompanhada de sintomatologia clínica; sua localização na cavidade orbitátária mas extra-ocular pode passar desapercebida clìnicamente.

A localização nervosa é a que se acompanha de manifestações mais graves. Poucas são as doenças do SNC que se caracterizam por quadros tão proteiformes como a cisticercose e são vários os fatôres que influem na determinação de formas clínicas tão diversas. Ao lado daquêles ligados ao número de parasitos, à sua localização, ao seu tipo e ao seu tamanho, influem aquêles relacionados às propriedades tóxicas e alérgicas do parasito, bem como os dependentes da variável capacidade de reação das estruturas do encéfalo. Trelles e Palomino ${ }^{47}$ chamam a atenção para êsses fatôres, salientando que é difcil separar o papel próprio a cada um dêles; é possível reconhecer a maior participação eventual de um ou outro, embora não sejam possíveis conclusões quanto à sua importância.

Ao iniciar-se o processo degenerativo do parasito ${ }^{3}$, o líquido da vesícula costuma apresentar-se turvo e são evidentes as alterações da membrana vesicular. Por sua vez o corpo é sede de degeneração lipofibromatosa, aparecendo corpúsculos hialinos. Em alguns casos as estruturas do corpo desaparecem, restando apenas massa hialina que preenche a vesícula. Esta também pode desintegrar-se e seu conteúdo perder-se nos tecidos circunvizinhos. Em outras ocasiões, as estruturas do parasito são substituídas por tecido fibrocolágeno, havendo deposição de sais calcáreos, originando-se cis- 
ticercos calcificados nos quais o arcabouço protêico do colágeno pode ser reconhecido mediante métodos especiais de coloração ${ }^{39}$.

Na cisticercose do SNC a sintomatologia pode decorrer de circunstâncias mecânicas e da reação imunopatológica, ou da combinação dêsses fatôres: os primeiros relacionam-se à interferência do parasito na drenagem do LCR ou, então, à compressão do parênquima nervoso; o segundo está ligado à reação inflamatória provocada pelo cisticerco, a qual pode transparecer de modos diversos, mas que parece ser provocada pelos catabolitos do parasito e/ou pelos produtos oriundos da sua desintegração. Por vêzes, a presença do parasito no SNC não se acompanha de qualquer dêsses fenômenos. Nesses casos o cisticerco pode constituir achado de autópsia, especialmente quando localizado em regiōes do encéfalo cujo comprometimento dificilmente se denuncia por sintomatologia clínica.

Se bem que o Cysticercus bovis, forma larvária da Taenia saginata (Goeze, 1782), possa eventualmente ser responsável pela cisticercose humana, é opinião geral que a cisticercose do SNC seja devida exclusivahente ao Cysticercus cellulosae ${ }^{38,40}$. Já o cenuro, larva de Taenia multiceps (Leke, 1880), pode muitas vêzes determinar doença semelhante à cisticer(cenurose) 15, 29, 36 .

Aspectos histopatológicos - Alguns aspectos da reação inflamatória desencadeada no tecido nervoso circunjacente ao parasito permitem deduções sôbre a imunopatologia da cisticercose. Embora haja referência à possibilidade do desencadeamento de reações inflamatórias de tipo agudo, na maioria dos casos a reação é de tipo sub-crônico e tem caráter localizado, acompanhando-se de fenômenos hiperérgicos locais.

Os produtos oriundos do metabolismo do parasito e/ou da sua desintegração podem desencadear reação inflamatória no SNC e nas leptomeninges ${ }^{46,47}$. Em geral, ela é localizada, sendo representada por focos inflamatórios junto ao cisticerco; em certos casos, porém, ela pode generalizar-se, determinando quadros de pan-encéfalo-meningite. Quando os cisticercos se localizam no parênquima, ao lado de alterações compressivas em vasos e células nervosas, surge reação inflamatória com proliferação do conjuntivo perivascular e da glia; ependimite e leptomeningite ocorrem quando os parasitos se localizam no espaço sub-aracnóideo ou nas cavidades ventriculares ${ }^{48}$.

A reação inflamatória tende a circunscrever os cisticercos situados no parênquima nervoso constituindo, ao seu redor, um verdadeiro granuloma no qual se distinguem três camadas: a mais interna, fenestrada, é rica em células epiletióides, macrófagos, células gigantes e polinucleares neutrófilos; a média é formada por tecido conjuntivo e colágeno, apresentando pequeno número de linfócitos e plasmócitos; a externa, rica em vasos, é formada por tecido de granulação em que sobressaem linfócitos, plasmócitos e fibroblastos, sendo encontráveis, também, células eosinófilas, polinucleares neutrófilos e gigantócitos.

A intensidade da reação inflamatória varia conforme a fase evolutiva dos cisticercos ${ }^{50}$. Ao redor daquêles mais jovens a reação é escassa, senđo 
representada por uma única camada de macrófagos e linfócitos; muitas vêzes essa camada não chega a circunscrever o parasito, sendo patente apenas ao nível do poro de invaginação. Ao redor daquêles que já apresentam sinais de desintegração a reação é mais intensa, sendo possível reconhecer as diferentes camadas acima descritas. Quando o parasito se encontra em avançado estadio de degeneração, as camadas apresentam certa desorganização, pela predominância de fibras conjuntivas e pela presença de grande número de macrófagos. Dos vasos circunvizinhos, então, estendem-se até o tecido de granulação fibras argentófilas que parecem participar do mecanismo de encapsulamento final do parasito. Nas vizinhanças do parasito são evidentes os fenômenos de esclerose capilar e pré-capilar, com obliteração da luz vascular. Nos vasos maiores há proliferação da íntima, sendo a adventícia sede de intensa infiltração celular, na qual predominam linfócitos e plasmócitos e da qual participam também células eosinófilas. Ao mesmo tempo há espessamento da túnica elástica e esclerose da meso-artéria. Nos estadios ainda mais avançados a parede vascular sofre degeneração hialina. Embora essas alterações sejam mais intensas nas paredes dos vasos próximos ao cisticerco, em certos casos podem apresentar-se de modo generalizado. Áreas de encefalomácia podem resultar da obliteração da luz vascular. Se bem que menos intensa, é semelhante a reação inflamatóriia observada nas paredes das veias. Ao redor do tecido inflamatório observa-se proliferação astrocítica e invasão microglial. Do comprometimento glial pode resultar o aparecimento de corpos grânulo-gordurosos.

Os neurônios próximos aos focos inflamatórios apresentam modificações que podem ser atribuídas à compressão e à ação tóxica. As lesões não atingem uniformemente todos os neurônios: ao lado de células conservadas encontram-se outras em adiantados estadios de degeneração. É particularmente em casos recentes que se observam fenômenos de degeneração neuronal aguda, marcados por inchação e cromatólise, seguidas de desintegração granular e liquefação do pirenóforo e dos dendritos. Picnose e cariólise constituem as principais alterações nucleares.

O infiltrado crônico à custa de elementos linfoplasmocitários, a tendência à formação de granuloma e a presença de células eosinófilas marcam as alterações inflamatórias do ponto de vista imunopatológico. Os fenômenos necróticos neuronais são indicativos da ação direta dos produtos liberados do cisticerco sôbre os elementos nobres do parênquima nervoso.

A reação inflamatória que se desenvolve nas leptomeninges geralmente não chega a circunscrever o cisticerco, caracterizando-se pela presença de tecido de granulação em que se distinguem fibras colágenas, infiltrado linfoplasmocitário, macrófagos e células eosinófilas; nas meninges da convexidade, costuma predominar o infiltrado celular, enquanto que a reação esclerosante é mais comum nas meninges da base. A ependimite que se desenvolve nas cavidades ventriculares, raramente circunscruvendo o parasito, assume, em geral, aspecto granuloso com hiperplasia fibroglial sub-ependimária.

Aspectos laboratoriais - Acompanhando a evolução dos conhecimentos sôbre o diagnóstico da cisticercose pode ter-se idéia geral do quadro imu- 
nobiológico da doença. Até a primeira década dêste século, o diagnóstico da doença era feito mediante a demonstração do parasito por ocasião do exame necroscópico. Depois desenvolveram-se métodos que tornaram possivel o diagnóstico em vida, salientando-se os baseados em exames radiológicos para identificação de cisticercos calcificados e em exames de laboratório para estudo da reação imunobiológica. Também neste setor são os dados sôbre a cisticercose do SNC aquêles que permitem visão mais detalhada sôbre o assunto.

A infestação do SNC e das leptomeninges pelo cisticerco costuma determinar alterações do LCR indicadoras de reação inflamatória do tipo crônico, mas que apresenta certas peculiaridades, permitindo conceituar a sindrome liquórica da neurocisticercose ${ }^{19}$. Caracteriza-se fundamentalmente essa síndrome pela ocorrência de pleocitose, acompanhada de eosinofilorraquia e pela presença de anticorpos específicos.

A pleocitose é observada com freqüência, sendo geralmente discreta e constituída predominantemente de elementos da linhagem linfomononuclear, ao lado dos quais podem ser encontrados polinucleares neutrófilos e células eosinófilas.

Em nossa experiência a eosinófilorraquia é observada em cêrca de $50 \%$ dos casos de cisticercose do SNC em que há pleocitose liquórica ${ }^{43}$. Geralmente não se encontram células eosinófilas no LCR quando o número total de leucócitos da amostra é normal. Por outro lado a eosinofilorraquia costuma ser proporcionalmente mais intensa quanto maior fôr a pleocitose. Na maioria das vêzes, entretanto, a percentagem de eosinófilos não é superior a $10 \%$ do total das células presentes. É variável o tipo de células eosinófilas encontradas no LCR: desde formas polinucleadas (semelhantes às encontradas no sangue), até formas mononucleadas bastante jovens ${ }^{17}$. Por vêzes, são encontrados agrupamentos de granulações eosinófilas livres.

Uma vez que a granulação eosinófila encerra enzima capaz de inibir a histamina ${ }^{51}$, a intensidade da eosinofilorraquia permite avaliar indiretamente o grau da liberação dessa substância. Essa liberação é devida, provàvelmente, ao caráter hiperérgico da reação desencadeada pelo parasito no SNC e nas leptomeninges. Reações dêsse tipo costumam ser inespecíficas e ocorrem em diversos tipos de processos patológicos, especialmente naquêles de natureza inflamatória ${ }^{18}$. Esta particularidade tira à eosinofilorraquia o caráter patognomônico admitido no passado ${ }^{35}$, pois ela pode ser encontrada em outras afecções do SNC. No entanto, na maioria destas outras condições, além de o exame do LCR oferecer outros elementos capazes de encaminhar o diagnóstico, a presença de células eosinófilas costuma ser eventual; além disso, seu número costuma ser reduzido, havendo tendência a desaparecerem ràpidamente, como se observa mediante exames sucessivos. Na cisticercose do SNC a eosinofilorraquia persiste em exames feitos em ocasióes diferentes ?

A presença de células eosinófilas no LCR tem sido descrita em outras afecções parasitárias do SNC, como na esquistossomose e na equinococose ${ }^{43}$. Entretanto, o caráter localizado da reação que estas afecções costumam determinar, raramente transparecendo por alteraçōes liquóricas, confere à 
cisticercose a primazia entre as afecções parasitárias do SNC que, em nosso meio, se acompanham de eosinofilorraquia. Na cisticercose é mais comum a participação das leptomeninges nos fenômenos imunopatológicos desencadeados em vista do que resulta, entre outros dados, a pleocitose liquórica da qual participam, com freqüência e por longo tempo, as células eosinófilas, marcando nìtidamente o caráter hiperérgico da reação inflamatória.

Ao lado da resposta imunobiológica inespecifica revelada pela eosinofilorraquia, na neurocisticercose costumam ocorrer fenômenos imunitários especificos, havendo formação de anticorpos. A presença dêstes pode ser demonstrada por reações imunodiagnósticas (reação de fixação do complemento e reação de precipitação).

A reação de fixação do complemento para o diagnóstico de parasitoses foi introduzida por Weinberg (1909) que, entretanto, conseguiu demonstrar a presença de anticorpos no sôro de paciente com cisticercose generalizada, embora tentasse diversos antígenos, entre os quais o líquido de vesícula parasitária retirada do mesmo paciente. Moses, no Brasil, em 1911, empregando extrato aquoso de cisticercos, foi o primeiro a demonstrar a positividade da reação de fixação do complemento no sôro de três pacientes com cisticercose e no LCR de um dêles. Em 1919, Guccione ${ }^{12}$ introduziu o emprêgo do extrato alcóolico de cisticercos como antígeno, método que foi empregado, em nosso meio, por Pessoa, Silveira e Correia (1926 a 1928). O exame entrou para a rotina dos métodos de laboratório clínico depois dos trabalhos de Lange 18 (1936) utilizando extrato alcóolico de vesículas cisticercóticas prèviamente tratadas pela acetona, preparado de acôrdo com técnica exposta em trabalho, feito sob sua orientação, por Monteiro Salles (1934). Êste é o antígeno mais empregado até o presente, tendo sofrido sucessivas modificações, conforme referiram Reilein, Trigueros e Alcalde ${ }^{32}$, em 1951. Magalhães ${ }^{24}$, em 1957, introduziu o emprêgo de antígeno obtido mediante extração metílica de cisticercos prèviamente tratados por benzeno.

Os anticorpos evidenciados mediante as reações de fixação do complemento têm especificidade apenas de grupo. Os fenômenos imunitários desencadeados na cisticercose se aproximam daquêles encontrados na infestação por outros cestóideos. O valor da reação no LCR se deve à pequena frequiência com que o SNC é parasitado, pelo menos em nosso meio, por cestóideos capazes de desencadear também reações leptomeníngeas difusas. A cenurose do SNC, por exemplo, dificilmente pode ser diferenciada da cisticercose do SNC mediante o estudo dos fenômenos imunitários evidenciados pelo exame do LCR, por serem semelhantes as reações inflamatórias provocadas por ambas.

Deve-se a Lange a difusão do emprêgo da reação de fixação do complemento no LCR para o diagnóstico da cisticercose do SNC ${ }^{19}$. Esse autor demonstrou a especificidade relativa da reação quando praticada no LCR e sua utilidade para o diagnóstico biológico da neurocisticercose. Hoje, no LCR, é o meio mais seguro para o diagnóstico da doença, conforme se depreende dos levantamentos feitos em regióes onde é elevada a incidência da neurocisticercose $8,13,14,22,27,28,53$. 
A possibilidade da ocorrência, no $L C R$, de reaçōes cruzadas, especialmente entre as reações de fixação do complemento para sífilis e para cisticercose torna aconselhável a feitura das duas reações ao mesmo tempo ${ }^{31}$. Nos casos duvidosos, além do restante do quadro liquórico poder orientar - raciocínio, costuma-se fazer simultâneamente ambas as reações pela técnica quantidativa, dando-se valor àquela que fôr positiva nas maiores diluições da amostra. O emprêgo de antígenos mais purificados e de técnicas mais precisas, como nas reações baseadas na hemólise parcial e em técnicas de isofixação ${ }^{24,33}$, reduz o risco de reações cruzadas.

A presença de anticorpos específicos pode ser demonstrada também por reações de precipitação, introduzidas por Trawinski e Rothfeld e cujo valor foi estudado por Biagi e Tay ${ }^{1}$, que aperfeiçoaram o antígeno e desenvolveram técnica que permite resultados mais precisos.

Também ocorrem alterações no proteinograma do $L C R$, constituídas por aumento discreto ou moderado da concentração protêica total e nítidas alterações de perfil protêico ${ }^{42}$. O perfil eletroforético das proteínas do LCR apresenta alterações qualitativas e quantitativas, salientando-se a ausência freqüente da pré-albumina, a ausência da fração táu e a predominância da globulina gama sôbre as demais globulinas. As alterações são adequadamente expressas pelas médias obtidas em uma série de 30 anos que estudamos: tendência a desaparecimento da pré-albumina $(0,9 \%)$; teores abaixo do normal para a albumina $(46 \%)$ e globulinas alfa-1 $(4,2 \%)$ e alfa-2 $(6,7 \%)$; teor de globulina beta diminuído $(14,2 \%)$ e de globulina gama aumentado $(28 \%)$. O estudo comparativo das alterações encontradas no LCR mostra que elas não são paralelas às que ocorrem no sôro. No LCR, a comparação entre a concentração de globulina gama e a intensidade da positividade da reação de fixação do complemento para cisticercose sugere que também nesta afecção os anticorpos específicos são ligados à fração gama ${ }^{42}$.

Êsses mesmos estudos permitiram verificar que as alterações do proteinograma na cisticercose do SNC apresentam peculiaridades em relação a processos que evoluem da mesma forma, como a meningoencefalite tuberculosa e a neurossífilis.

A análise dêsses dados permitiu demonstrar que as reações desencadeadas no SNC pelo cisticerco se caracterizam por alterações protêicas de duas ordens: uma peculiar à albumina e às globulinas alfa e beta e, outra, à globulina gama, As alterações nos teores da albumina e das globulinas alfa e beta parecem decorrer de comprometimento da barreira hêmato-liquórica. As alterações no teor da globulina gama, além de sugerirem a participação das proteínas dêsse grupo no transporte de anticorpos específicos, permitem relacionar essa globulina à atividade dos elementos do sistema retículo-endotelial (SRE) sediados no SNC e em seus envoltórios, encarregados da reação imunopatológica de defesa. Um dos argumentos mais ponderáveis para justificar a assertiva de que essa globulina é gerada pelo SRE resultou de estudos sôbre a passagem da globulina gama do sôro para o LCR utilizando iôdo-radiativo ${ }^{9}$. Tais estudos demonstraram que essa 
fração passa do sôro para o LCR de modo mais lento que a albumina e que, em condições normais, todo o contingente presente no LCR é representado pela porção proveniente do sangue; entretanto em processos inflamatórios crônicos do SNC e das leptomeninges essa fração resulta, em sua maior parte, da elaboração local. Cisticercos, uma vez instalados no SNC, são capazes de desencadear reações inflamatórias que se acompanham de aumento acentuado de produção de globulina gama, a qual dá a medida da intensidade dos fenômenos imuno-alérgicos desencadeados, além de participar do transporte de anticorpos específicos ${ }^{42}$.

Por outro lado, estudos do perfil protêico do LCR na cisticercose têm permitido verificar que a reação imuno-alérgica não se acompanha de lesões parenquimatosas com a mesma intensidade das que são observadas em outros processos inflamatórios crônicos, como a neurossífilis. As observações quanto ao comportamento do índice beta globulina/albumina têm permitido configurar nitidamente essa diferença entre os fenômenos imunopatológicos que acompanham uma e outra doença ${ }^{45}$.

A reação imunobiológica desencadeada pela cisticercose do SNC apresenta maior intensidade no LCR do espaço sub-aracnóideo que naquêle do sistema ventricular ${ }^{44}$. Por outro lado, a evolução do quadro liquórico da neurocicisticercose costuma ser variável e nem sempre acompanha a evolução do quadro clínico. Em geral, a evolução satisfatória é caracterizada pelo progressivo desaparecimento das alterações do LCR; se estas se mantiverem por longo tempo o prognóstico é mais reservado especialmente quando se instala hipoglicorraquia de intensidade progressivamente maior ${ }^{25}$. Por vêzes, nas fases iniciais observam-se apenas alterações inespecíficas, como a pleocitose, surgindo, depois, a eosinofilorraquia e os anticorpos específicos.

Também na reação imuno-biológica liquórica há elementos sugestivos de que os fenômenos sejam desencadeados por catabolitos do parasito ou por produtos de sua desintegração. Assim, é comum a observação de quadros liquóricos normais quando o parasito ainda está íntegro. Em geral, nesses casos são os pacientes submetidos a intervenções cirúrgicas devido a bloqueio de uma das passagens angustiadas do sistema liquórico e o diagnóstico resulta do achado do cisticerco pelo neurocirurgião. Por outro lado, a rotura de cisticerco durante ato cirúrgico pode desencadear exacerbação ào quadro liquórico, assumindo êste caráter meningítico. A explicação dessa ocorrência pode estar relacionada ao poder antigênico do líquido da vesícula parasitária.

A remoção cirúrgica de parasitos em casos de infestação discreta do SNC é, geralmente, seguida de remissão das alterações do LCR. Quando a infestação é severa não se observa regressão das alterações liquóricas, podendo ocorrer apenas flutuaçōes na intensidade da reação inflamatória Só tardiamente, no caso de todos os parasitos terem sido completamente destruídos é que há possibilidade de normalização do quadro liquórico.

É nesta última fase da evolução da doença que são freqüentes as imagens radiológicas características de cisticercos calcificados. $\mathrm{Na}$ maioria das vêzes tais imagens permitem fazer o diagnóstico "a posteriore" da doença. 
Em geral, nas fases em que o exame do LCR permite evidenciar a atividade dos fenômenos imunobiológicos, não existem tais imagens. Sòmente em casos raros coexistem sinais radiológicos de cisticercos calcificados e síndrome liquórica da neurocisticercose.

A elevada incidência de infestações do organismo humano por outros parasitos que desencadeiam reações imuno-alérgicas gerais explica porque a constatação de eosinofilia sangüínea não tenha grande valor para o diagnóstico de cisticercose. O mesmo pode ser dito quanto ao valor da positividade das reações de imunodiagnóstico no sôr.o sangüíneo. Sendo a especificidade delas apenas de grupo, podem ser positivas em casos de infestação por outros cestóides e por parasitos que desencadeiem reações semelhantes. Isto se dá na infestação das diferentes estruturas do meio interno por outros cestóides e, também, na presença das formas adultas de tênia no tracto intestinal. Além disso, os fenômenos imunitários desencadeados na cisticercose freqüentemente se restringem às estruturas que circunscrevem o parasito, do que resulta a possibilidade de não serem evidenciados anticorpos específicos no sôro sangüínieo. Em análise que fizemos de uma série de pacientes com neurocisticercose ${ }^{41}$, foi computada a freqüência da eosinofilia e da positividade da reação de fixação do complemento no sôro sangüíneo, tendo sido verificado que $\mathrm{em}$ grande número de casos essas anormalidades não ocorriam.

Há outros exames que podem indicar, também, a ocorrência das alterações imunobiológicas na cisticercose. Entre êles salienta-se a intradermorreação com líquido de cisticerco (cutirreação de Robin-Fiesinger); quando positiva, há formação de pápula eritematosa e pruriginosa após cêrca de 15 minutos, permanecendo por pelo menos 30 minutos e sendo substituída, depois, por edema subcutâneo que persiste por 24 horas. Para obter maior especificidade nessa prova aconselham alguns autores o emprêgo do líquido de cisticerco retirado do homem. O emprêgo da cutirreação não é muito difundido por apresentar especificidade menor que a das reações imunológicas, pois costumam ocorrer reações cruzadas no parasitismo por quase todos os demais cestóides.

A especificidade de grupo das reações imuno-alérgicas da cisticercose pode ser evidenciada pelos resultados obtidos mediante a intradermorreação de Casoni e a reação de fixação do complemento para hidatidose (reação de Weinberg pròpriamente dita). Em ambas o antígeno é constituído pelo líquido do cisto hidático e resultados positivos podem ser observados também em casos de cisticercose.

No sangue, além da eosinofilia, pode ocorrer leucocitose discreta ou moderada, com neutrofilia e ligeira linfopenia; a hemossedimentação pode estar discretamente aumentada. O proteinograma do sôro pode evidenciar aumento da globulina gama ${ }^{41}$; êste aumento é achado menos comum que no LCR e, geralmente, não atinge a intensidade do aumento verificado neste último. Por vêzes há, também, ligeiro aumento da concentração das globulinas alfa-1 e/ou alfa-2. 
Assim, apesar dos progressos feitos nos últimos 20 anos, ainda falta muito para que sejam completados os estudos sôbre a imunobiologia da cisticercose, sendo numerosas as lacunas que se interpõem entre os conhecimentos existentes. $\dot{\mathbf{A}}$ falta de estudos experimentais, um dos principais fatôres responsáveis por essas lacunas, aliam-se deficiências oriundas das dificuldades inerentes aos estudos de imunopatologia das moléstias parasitárias. Métodos de imunodifusão, de imunoeletroforese e de imunofluorescência vêm sendo aplicados nas pesquisas sôbre a cisticercose, prometendo abrir novos horizontes no conhecimento da imunobiologia da doença. As propriedades biológicas das várias modalidades de imunoglobulinas, especialmente sua capacidade de resposta aos estímulos antigênicos desencadeados pelo parasito no organismo do hospedeiro e a natureza das reações resultantes são alguns dos problemas cujo estudo poderá ser melhor orientado mediante o emprêgo dêsses métodos. Além de contribuirem para a solução das questões relacionadas diretamente à cisticercose, poderão permitir avanços úteis no estudo da infestação do sistema nervoso humano por outros parasitos animais.

\section{R E S U M O}

O autor procura avaliar os problemas ligados à imunobiologia da cisticercose e os recursos laboratoriais atualmente existentes para o diagnóstico baseando-se, especialmente, em dados sôbre a infestação do sistema nervoso central. A análise é conduzida mediante revisão de conhecimentos relacionado à biologia do cisticerco, ao quadro histopatológico por êle desencadeado e às reações biológicas que se patenteiam em exames paraclínicos. Êsses fatôres são discutidos $\in m$ relação a aspectos peculiares da doença e orientam as conclusões, entre as quais é apontada a necessidade de estudos mediante experimentação animal e a oportunidade de estudos sôbre imunoproteínas para o esclarecimento de pontos ainda duvidosos da patogenia.

\section{S U M M A R Y}

Immunobiology of cysticercosis. An evaluation of present concepts.

Present concepts on the immunobiology of cysticercosis are reviwed considering the experience on cysticercosis of the central nervous system. For this puspose data related to cysticercus biology, to histopathology of the disease, to biologic aspects evidenced through laboratory investigations and radiology are discussed and evaluated. The lack of experimental studies is stressed and the importance of studies on immunoproteins are pointed out. Informations resulting from these studies might explain many of the doubts that are patent when the concepts on the pathogeny of the disease are considered. 


\section{REFER EN CIAS}

1. BIAGI F. F. \& TAY, J. - A precipitation reaction for the diagnosis of cysticercosis. Am. J. trop. Med. Hyg. 7:63, 1958

2. BICKERSTAFF, E R.; SMALL, T. M. \& WOLF, A. L. - Cysticercosis of the posterior fossa. Brain $79: 622,1956$.

3. BRICENO, C. E.; BIAGI, F. \& MARTINEZ, B. - Cisticercosis. Observaciones sobre 97 casos de autopsia. Prensa Med. Mexic. 26:193, 1961.

4. BRINCK, G. - La Cisticercosis Cerebral. Tese. Santiago (Chile), 1940.

5. CANELAS, H. M. - Neurocisticercose: incidência, diagnóstico e formas clinicas. Arq. Neuro-Psiquiat. (São Paulo) 20:1, 1962.

6. COMITÉ O.M.S. - Immunologie et maladies parasitaires. Chronique O.M.S. 20:96, 1966.

7. CUADRA, M. - Cisticercosis cerebral y eosinofilia raquidea. Rev. NeuroPsiquiat. (São Paulo) 12:339, 1949.

8. ESCOBAR, T. A. - Cisticercosis cerebral. Arq. mexic. Neurol. Psiquiat. 1:149, 1952.

9. FRICK, E \& SCHEID-SEIDEL, L. - Untersuchungen mit $\mathrm{I}_{131}$ markierten Gamma-globulin zur Frage der Abstammung der Liquoreiweisskörper. Klin. Wchschr. 36:857, 1958.

10. GARBUTT, G. D, \& COURVIlle, C. B. - Cysticercosis cerebri. A retrospective study including 14 new cases personally investigated. Bull. Los Angeles Neurol. Soc. 32:6, 1967.

11. GREENSPAN, G. \& STEVENS, L. - Infection with cysticercus cellulosae: report of a case. New England. J. Med. 264:751, 1961.

12. GUCCIONE, A. - La Cisticercosis del Sistema Nervoso Centrale Umano. Soc. Ed. Libraria, Milano, 1919.

13. IIZUKA, H. - Observaciones Clínicas sobre la Neurocisticercosis. Editorial Paz Montalvo, Madrid, 1961.

14. ISAMAT DE LA RIVA, F. - Cisticercosis Cerebral. Vergara SA., Barcelona, 1957.

15. KUPER, S.; MENDELOW, H. \& PROCTOR, N. S. F. - Internal hydrocephalus caused by parasitic cysts. Brain 81:235, 1958.

16. LAFON, R.; LABANGE, A.; RIBSTEIN, M. \& BARJON, M. C. - Les eosinophiles du liquide céphalo-rachidien: la meningite aigue curable à eosinophiles. Rev. Neurol. 97:466, 1957.

17. LANGE, O. - Sôbre as células eosinófilas do líquido céfalorraqueano. Rev. Neurol. Psiquiat. de São Paulo 1:421, 1935. 
18. LANGE, O. - O liquido cefalorraqueano na cisticercose do sistema nervoso central. Rev. Neurol. Psiquiat. de São Paulo 2:3, 1936.

19. LANGE, O. - Síndrome liquórica da cisticercose encéfalo-meningea. Rev. Neurol. Psiquiat. de São Paulo 6:35, 1940.

20. LEFEVRE, A. B. - Estudo clínico dos tumores intracranianos em crianças; considerações a propósito de 127 casos. Rev. Hosp. das Clínicas 21:1, 1966.

21. LOMBARDO, L. \& MATEOS, T. H. - Central cysticercosis in Mexico. Neurology (Minneapolis) 11:824-828, 1961.

22. MAC ALPINE, L.; ZAINO, L. J. \& DE SANTO, D. A. - Cysticercosis cerebri. Prog. Meet. Amer. Soc. Clin. Pathol. a. Coll. Amer. Pathol., outubro 15-23, página 92, 1965 .

23. MAGALHÃES, A. E. de A. - Contribuição para o estudo da reação de fixação do complemento com antígeno de Cysticercus cellulosae. Tese, Ribeirão Prêto (São Paulo), 1957.

24. MAGAlHães, A. E. de A. - Reação de fixação do complemento para cisticercose no liquido cefalorraqueano. Arq. Neuro-Psiquiat. (São Paulo) 15:183, 1957.

25. MEGA, D. \& LISON, M. P. - Hypoglycorachie et cysticercose cérebromeningée. Schw. Arch. Neurol. Neurochir. Psychiat. 100:425, 1967.

26. NAPANGA, T. - Reaccion de fijacion del complemento en la cisticercosis. Rev. Med. Hosp. Obrero (Lima) 2:121, 1953.

27. NIETO, C. - Cysticercosis of the central neurvous system. Diagnosis by means of spinal fluid complement fixation test. Neurology (Minneapolis) $6: 725,1956$.

28. OBRADOR, S. - Cysticercosis cerebri. Acta neurochirurg. 10:320, 1962.

29. PROCTOR, N. S. F. - Problems associated with tapeworm cyst infestation of the central nervous system. In van Bogaert, L.; Pereyra Kafer, J. \& Poch, G. F. - Tropical Neurology. Lopez Libreros Editores, Buenos Aires, pág. 140-148, 1963.

30. PUPO, P. P. - Cysticercosis of the central nervous system: clinical manifestations. Rev. Neuro-Psiquiat. (Lima) 27:'70, 1964.

31. PUPO, P. P.; CARdoso, W.; REIS, J. B. dos \& PEREIRA DA SILVA, C. Sôbre o cisticercose encefálica. Estudo clínico, anátomo-patológico, radiológico e do liquido cefalorraqueano. Arq. Assist. Psicop. Estado de São Paulo 10-11: 3-125, 1945-1946.

32. REINLEIN, J. M. A.; TRIgueros, E. A. \& ALCALDE, S. O. - The study of cerebrospinal fluid in diagnosis of cysticercosis of the central nervous system Bull. Inst. med. Res. (Madrid) 4:65, 1951.

33. REIS, J. B. dos \& BEI, A - A reação de fixação do complemento para o diagnóstico da sífilis e da cisticercose no liquido cefalorraqueano pela técnica de Wadsworth, Maltaner e Maltaner. Rev, paulista Med., 53:439, 1958. 
34. REIS, J. B.; BEI, A. \& DINIZ, H. B. - Dificuldade no diagnóstico diferencial entre a cisticercose encefálica e neurolues. Arq. Neuro-Psiquiat (São Paulo) 7:156, 1949.

35. RIZZO, C. - La diagnosi biologica di cisticercosi del nevrasse. Rev. Patol. nerv. ment. 41:193, 1933.

36. ROBINSON, R. G. - Coenurosis of the central nervous system. World Neurol. $3: 35,1962$.

37. ROCCA, E. D. - Cisticercosis intramedular. Rev. Neuro-Psiqliat. (Lima) 22: 166, 1959.

38. SLAIS, J. - Zur Morphologie und Entstehung der invaginierten cysticerken mit einem herausgewachsenen Skolex. Z. F. Parasintenh. 27:25, 1966.

39. SLAIS, J. - Der Nachweis der Parasiten und die Gewebsreaktion bei der Gehirncysticercose. Cs. Parazitol. 12:263, 1965.

40. SLAIS, J. - The morphology of the parasite in cerebral cysticercosis. Cs. Patol. 1:65, 1965.

41. SPINA-FRANÇA, A. - Cisticercose do sistema nervoso central. Consideraçõe sôbre 50 casos. Rev. Paulista Med. 48:59, 1956.

42. SPINA-FRANÇA, A. - Valor do exame e etroforético das proteínas do líquido cefalorraqueano na cisticercose do sistema nervoso central. Arq. Neuro-Psiquiat. (São Paulo) 18:301, 1960.

43. SPINA-FRANÇA, A. - Sindrome liquórica da neurocisticercose. Arq. Neuro-Psiquiat. (São Paulo) 19:287, 1961.

44. SPINA-FRANÇA, A. - Aspectos biológicos da neurocisticercose: alteraçōes do líquido cefalorraqueano. Arq. Neuro-Psiquiat. (São Paulo) 20:17, 1962.

45. SPINA-FRANCA, A. - Globulina beta do líquido cefalorraqueano no prognóstico de processos inflamatórios do sistema nervoso central. Arq. Neuro-Psiquiat. (São Paulo) 22:1, 1964.

46. TRELlES, J. O. \& LAZARTE, J. A. - Cisticercosis cerebral: estudio clínico, histopatológico y parasitológico. Rev. Neuro-Psiquiat. (Lima), suplemento, 1941.

47. TRELLES, J. O. \& PALOMINO, L. - Histopatology of cerebral cysticercosis. In van Bogaert, L.; Pereyra Kafer, J. \& Poch, G. F. - Tropical Neurology. Lopez Libreros Editores, Buenos Aires, pá g. 162-182, 1963.

48. TRELlES, J. O.; ROCCA, E. \& RAVENS R. - Estudios sobre neurocisticercosis: lesiones vasculares, meningeas, ependimarias y neuroglicas. Rev. Neuro-Psiquiat. (Lima) 16:241, 1953.

49. TRELLES, J. O.; ROCCA, E. \& RAVENS, R. - Estudios sobre neurocisticercosis: sobre la fina estructura de la memırana vesicular quística y racemosa. Deducciones patológicas. Rev. Neuro-Psiquıat. (Lima) 15:1, 1952.

50. TRELlES, J. O. \& ROEDENBECK, S. D. - Estudios sobre neurocisticercosis: formas clinicas poco frecuentes. Rev, Neuro-Psiquiat. (Lima) 17:15, 1954. 
51. VERCAUTEREN, R. - The properties of the isolated granules from blood eosinophiles. Enzymologia 16-1, 1953.

52. WHITE, J. C.; SWEET,, W. H. \& RICHARDSON, E. P. - Cysticercosis cerebri: a diagnostic and therapeutic problem of increasing importance. J. nerv. ment. Dis. 122:107, 1955.

53. ZOZULYA, J. A. \& SKLYARENKO, N. I. - The importance of complement fixation reaction with the cysticercoid antigen in the diagnosis of cysticercosis of the brain. Vop. Neirokir. (Moscou) 22:28, 1958.

Clinica Neurológica - Faculdade de Medicina, Universidade de São Paulo - Caixa Postal 3461 - São Paulo, SP - Brasil. 